\title{
Patrimônio cultural:
}

\section{saberes e fazeres no discurso cultural-epistemológico}

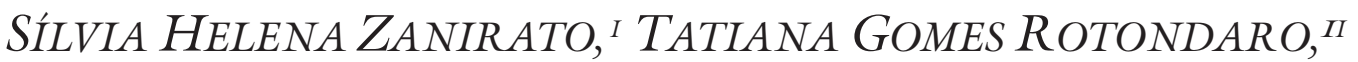 \\ MARIA LETÍCIA MAZZUCCHI FERREIRA ${ }^{I I I}$ e CYRIL ISNART IV
}

\section{Introdução}

A DIVISÃO NATUREZA e cultura em reinos separados em termos ontológicos e epistemológicos é uma das bases do conhecimento moderno e de como as sociedades modernas são reguladas (Jones, 2009), numa lógica que divide, define e classifica para então explicar. Essa divisão fundamenta a separação mente/corpo, sujeito/objeto, real/imaginário, material/imaterial e considera o homem como ator principal e a natureza como o destinatário passivo, externo à ação.

O dualismo é visível nas formulações das ciências sociais e ciências naturais, na negação da agência na natureza e sua exclusão nas formulações históricas, políticas e éticas dominantes (Jones, 2009). Ele igualmente fundamenta compreensões acerca da conservação da natureza ao considerar que a proteção deve ocorrer separada da sociedade, em reservas naturais, sem levar em conta que a natureza não é um estágio passivo na história humana, mas um dos principais atores do programa (Jones, 2009). A separação também se expressa no entendimento de patrimônio cultural, uma formulação do conhecimento moderno, que, de modo geral, considera como herança cultural os edifícios e obras de engenharia, artes e ofícios, idiomas e tradições e raramente as criações originadas na interação homem/natureza, ou mesmo as terras e os mares que habitamos e exploramos, os solos, plantas e animais que constituem os ecossistemas do mundo, a água que bebemos, o próprio ar que respiramos (Lowenthal, 2005).

No entanto, o patrimônio em um sentido amplo é bem mais híbrido do que se afirma. Em sua aplicação se justapõem o natural/cultural-social, o tangí$\mathrm{vel/intangível} \mathrm{e} \mathrm{o} \mathrm{objetivo/subjetivo.}$

Com vistas a particularizar essa condição é que o artigo se volta. Nele são discutidas as formas de pensamento que separaram cultura e natureza, que originaram a busca por um conhecimento tido como puro, a influência desse tipo de pensamento na formulação inicial e os desdobramentos que articularam e incorporaram aspectos naturais e intangíveis e explicitaram a pluralidade semântica dessa categoria analítica. Os desafios de proteção de bens, num cenário de 
aceleradas transformações sociais, também se vinculam à concepção mais holística do conceito.

\section{Culturalização da natureza/naturalização da cultura}

Poucos temas apresentam uma história tão controversa na filosofia das ciências quanto a dicotomia natureza e cultura, que mobiliza em maior ou menor grau esforços intelectuais de cientistas sociais e naturais.

Não seria exagero dizer que essa dicotomia repousa na base do conjunto de disciplinas (Florit, 2000), que resultaram em compreensões da natureza como uma realidade externa ao homem, objetiva, a ser compreendida e dominada pelas ciências físicas, químicas, biológicas, e dos fazeres humanos no controle dessa realidade, apreendidos pela sociologia, antropologia, história, economia, psicologia. Nessa relação se viram duas zonas ontológicas distintas: a primeira dos fazeres humanos, culturais e sociais, caracterizados pela subjetividade; e a segunda do mundo natural, no qual reina a objetividade (Latour, 1993, 2004).

$\mathrm{Na}$ busca pela razão tanto para apreender o movimento da realidade quanto para intervir nela é que se compreende o sentido que a cultura adquiriu, vista como progresso, evolução, razão; um preceito comparativo em relação a outras formas ou estilos de vida, numa perspectiva evolucionista, da selvageria à civilização.

A cultura foi tida como a norteadora do uso da razão, inventiva, ativa, capaz de construir os conhecimentos para colocar o homem acima da natureza e criar o mundo material. A natureza, por sua vez, foi considerada uma entidade externa, passiva, dotada de recursos a serem explorados para satisfazer as necessidades humanas.

Natureza e cultura como entidades separadas inserem-se, assim, na constituição do pensamento moderno ocidental e na expectativa de um conhecimento verdadeiro, puro, objetivo.

Em termos biológicos, a "pureza" resulta da ideia de "isolamento" (ou “endogamia"), levando à homozigose biológica (ou neidade genética). Em termos culturais, ela deriva do "refinamento" ou "convencionalização" de processos tradicionais, às vezes assistidos por autoritarismo, por tamanho pequeno e por uma seleção de velocidade na adaptação a novos ambientes - e minimização da variabilidade dentro da tradição cultural, uma condição associada à homogeneidade. Puro, significa ter características relativamente homogêneas (homozigoto em termos biológicos), com menor variação interna. Seu oposto seria o híbrido, heterogêneo em sua composição (Stross, 1999).

A especialização engendrada no âmbito acadêmico a partir do século XIX relegou às ciências sociais a tarefa de explicar as relações das sociedades modernas, o que implicou delimitar o social da forma mais abrangente possível (Comissão Gulbenkian, 1996), afirmando, por exemplo, que nas sociedades modernas só seria possível pensar na existência de uma natureza socializada. Como consequência, a categoria "natureza" em termos sociológicos tendeu a aparecer 
como residual. Levar o ideal científico ao âmbito do estritamente social implicou a taxativa avaliação de que os processos que envolvem os seres humanos são históricos e não naturais.

"Os fenômenos sociais não são naturais", esse foi o axioma fundador do mainstream do pensamento sociológico sistemático - conforme mencionado por Durkheim (1984), Weber (1997) e Parsons (1961), uma forma de pensar que delimitou "sociedade" e "natureza" como componentes epistemológicos antagônicos (Latour, 1994).

Todavia, a estabilidade da fronteira foi abalada, sobretudo, a partir da explosão das biotecnologias e da genômica na década de 1990, quando proliferou uma literatura perplexa e alarmada com o estatuto e o futuro da vida em geral, e da natureza humana em particular e fez com que tudo que até então se compreendia como natural (biológico) e base da vida social, se tornasse artefato manipulável por meio de tecnologias reprodutivas (celular ou genômica). Tal feito levou, de forma até então inimaginável, a um avanço no processo de culturalização da natureza (Leite, 2003). A implosão de fronteiras entre natureza e cultura impulsionou o reconhecimento científico de objetos híbridos.

Tem-se então o entendimento de que a natureza é "um departamento da empresa humana" e que a distinção entre o natural e o cultural é uma "construção cultural como sempre havia sido" (Strathern, 1992, p.55). Um dos desdobramentos desse entendimento foi o de que "o próprio meio ambiente, seja ele tradicionalmente entendido como natural ou cultural, não se encontra mais alheio à vida social humana, mas é perpassado e reordenado por ela. Se houve um dia em que os seres humanos souberam o que era a 'natureza', agora não o sabem mais" (Beck, 1997, p.8).

Isso levou Sarah Franklin a cunhar uma releitura conceitual de Própria Vida (Life Itself):

A natureza pode-se dizer, tem sido des-tradicionalizada. [...] Isso não significa que ela seja menos útil, como já argumentamos, mas a natureza entrou em parafuso. No lugar antes ocupado por "fatos naturais" há um novo quadro de referência, um rebento da era genômica, que é a própria vida - agora órfã da história natural, mas cheia de promessas deslumbrantes (dazzling). (Franklin, 2000, p.190-1)

Implicações dessas mudanças se expressaram nas formulações sobre patrimônio, um conceito também criado pelo pensamento moderno ocidental.

\section{O patrimônio como categoria conceitual}

Hoje temos que o conceito patrimônio é ambíguo, polissêmico; uma construção social cujo significado se reveste de diferentes atributos conforme quem o emprega, o tempo histórico e a finalidade com que o emprega (Poulot, 2009). Há um labirinto de significados (Bonfil-Batalla, 1997) e se pode até dizer que "não existe o patrimônio em si, mas sim certas categorizações e qualificações que são socialmente construídas" (Valdebenito, 2005, p.289). 
O entendimento do vocábulo remete tanto aos regimes de ação, que constroem sentidos sociais de pertencimento, quanto ao direito privado e administrativo, vinculado à propriedade privada. Quando se fala em patrimônio cultural, a expressão é transportada a outro campo e se refere a um conjunto específico de ações institucionais que se aplicam a elementos considerados acervo da sociedade (Ariño, 2007). Os elementos convertidos em patrimônio passam a ter um sentido particular e são submetidos a um modo específico de gestão (Poulot, 2009). Nesse processo, o objeto ou lugar muda de status, seu repertório de significado e de usos se altera (Rautenberg, 2010).

Essa mudança é denominada por Natalie Heinich como artificação, ou seja, alterações pelas quais passa o elemento patrimonializável, cultural ou natural e que são de ordem semântica, jurídica, cognitiva (Heinich, 2014). Para isso, o elemento é extraído ou deslocado de seu contexto inicial (um pré-requisito para a artificação), alterado terminologicamente (passa a ser conceituado como monumento histórico, obra-prima, artística, espaço natural protegido), normatizado por dispositivos jurídicos (acautelado pelo poder público por instrumentos como registro, chancela, tombamento) e inserido em discursos que reiteram sua excepcional condição (Shapiro; Heinich, 2013).

Esse tipo de ação difere do que se entende como patrimônio por regimes de ação: um bem assim considerado por apropriação social, valorado por sentimentos, por significações construídas na relação com o tempo, com a continuidade. Isso permite dizer que há um patrimônio formado pelos "regimes de ação" e um patrimônio instituído, uma patrimonialização institucional, que altera o status de objetos e lugares (Bonfil-Batalla, 1997; Rautenberg, 2010; Heinich, 2014).

O patrimônio discutido neste texto é o instituído, uma construção social, "uma categoria eminentemente ocidental e que acompanha a história dessa civilização" (Hartog, 2003, p.163-206). Não é algo natural, nem eterno, nem estático. Sua significação foi produzida na configuração dos Estados modernos, ao se defender a existência de uma herança pública a ser preservada para o futuro.

\section{A construção social do patrimônio instituído}

Natureza e cultura são categorias fundamentais empregadas nos discursos e práticas em torno à patrimonialização a expressar entendimentos que reforçaram a dualidade concebida na Modernidade.

O patrimônio cultural ativado ou instituído - algo assim considerado por ações procedentes de instituição pública - tem sua origem vinculada às preocupações com as perdas da criação humana, consequentes da Revolução Francesa e das Guerras Napoleônicas. Esse sentido foi estabelecido mais claramente em 1837, na primeira Comissão dos Monumentos Históricos da França, tendo como objeto patrimonializável fundamentalmente a arquitetura, cuja seleção era definida por critérios que privilegiavam a materialidade, a monumentalidade, a ancianidade; os valores históricos, artísticos, técnicos e científicos do bem. Nesse 
entendimento o olhar especializado se voltava para a manufatura remanescente da Antiguidade e da Idade Média: abadias, catedrais, castelos, fortificações, símbolos do poder, tidos como expressão da genialidade criativa dos antepassados e que mostravam a cultura ilustrada, o processo evolutivo da sociedade rumo à civilização (Choay, 2001). A proteção pública a esses bens era feita em nome do povo, "destinatário eminente e, ao mesmo tempo, o derradeiro responsável por essa herança” (Poulot, 2009, p.26).

A seleção dos objetos vinha ao encontro de um entendimento da disciplina História, centrada em fatos singulares e excepcionais, nos personagens da elite, nas minúcias dos grandes acontecimentos capazes de mostrar a evolução das ações humanas, seu aprimoramento e seu caminhar em direção à civilização, ao progresso. Como lembra Poulot $(2009$, p.71), a História era a "narrativa feita com arte; descrição, narração consistente, ininterrupta e verdadeira dos fatos mais memoráveis e das ações mais célebres”. A eleição do que seria patrimonializado também levava em consideração a Arte, cuja história se tornara uma disciplina científica, concebida a partir de critérios que priorizavam a beleza plástica, as formas. Com esse arcabouço, as obras convertidas em patrimônio eram objetos de dileção estética e também de interesse e classificação científica, selecionados a partir de valores como autenticidade, integridade e excepcionalidade.

Para perpetuar sua permanência, as obras elevadas à condição de patrimônio deveriam ser isoladas do uso e disponíveis apenas para a contemplação. O mesmo juízo se aplicava aos espaços urbanos portadores de uma arquitetura considerada histórico/artística, vistos como monumentos que não podiam ser utilizados, mas apreciados para garantir sua integridade. Sua função era propedêutica, um testemunho das ações do homem no passado; por isso a preocupação em "preservar os conjuntos urbanos antigos como se conservam os objetos de museus", ou seja, com restritos usos (Choay, 2001).

A proteção pública era o requisito para conservação não só para os contemporâneos, mas para as gerações futuras. Por isso, a preocupação com a integridade física, com ações de preservação e restauro, mediante a especialização científica, na expectativa de "conservá-lo como foi encontrado" (Smith, 2011).

Essa retórica patrimonial foi repetida por discursos autorizados do Estado, fundados em disciplinas científicas como a Arquitetura, a Arqueologia e a História, e se tornou o entendimento mais comum do ser patrimônio.

A patrimonialização da natureza emergiu quase ao mesmo tempo em que a de bens culturais e foi resultante de entendimentos de que o crescimento populacional, o aumento da área cultivada, a industrialização e a expansão urbana se faziam à custa dos ecossistemas naturais (McCormick, 1992; Nash, 2014).

$\mathrm{Na}$ década de 1840, George Perkins Marsh expôs as consequências do impacto humano sobre o meio ambiente e propôs ações corretivas para conter $\mathrm{O}$ desmatamento e a erosão do solo. Em sua publicação de 1864, Man and Natu$r e$, Marsh argumentou que, sem uma reforma drástica, a humanidade reduziria 
a Terra às condições estéreis da Lua (Lowenthal, 2005). Às preocupações de Marsh se somaram as de Henry David Thoreau (1817-1862) sobre a extinção de povos indígenas e animais silvestres pelo avanço da fronteira, com argumentos a favor da criação de reservas naturais onde indígenas e animais pudessem sobreviver (Nash, 2014).

Todavia, concepções acerca da degradação causada pela presença humana, associadas aos entendimentos de natureza com entidade autônoma, fizeram com que o ambiente fosse considerado um bem em si mesmo. É o que se pode ver por ocasião da criação de parques naturais como o de Yellowstone (1872), nos Estados Unidos, uma área com significativa diversidade biológica e de grande beleza cênica, que deveria ser mantida, pela ação do Estado, intocada e livre de qualquer pressão humana para as gerações futuras. A argumentação foi a de que cabia ao poder público proteger o lugar para as gerações futuras e de que a conservação deveria ocorrer sem a presença humana, ainda que populações tradicionais tivessem modos de vida seculares no ambiente. O deslocamento de grupos humanos foi considerado condição necessária para a manutenção da beleza e dos bens naturais, e admitidas apenas a pesquisa e visitação turística para reconhecimento dos atributos naturais e estéticos, numa perspectiva propedêutica (Nash, 2014).

Os mesmos argumentos para a proteção de áreas tidas como pouco alteradas foram usados pelo Canadá ao criar seu primeiro parque nacional em 1885, pela Nova Zelândia em 1894, pela África do Sul e pela Austrália em 1898, pelo México em 1894, pela Argentina em 1903 e pelo Chile em 1926, sempre em territórios onde havia a presença de povos tradicionais. O sentido era o de afastar a população e manter a intocabilidade do lugar na expectativa de que a natureza regenerasse e se mantivesse estável. Havia que proteger os bens naturais tidos como de pertencimento coletivo, mesmo que houvesse a perda do conhecimento local das populações moradoras, de seus valores, símbolos, crenças e mitos, o que justificava a gestão pública para a vigilância, apropriação e eficiência científica no uso dos bens.

Assim, bens culturais e naturais passaram a ser apresentados como herança do povo, na acepção de algo público (independentemente de ser propriedade de alguém), de ser extensivo a todos (independentemente da representação majoritária dos bens de elite, da exclusão de populações tradicionais, do processo de gestão de tais bens que pôs em confronto saberes científico e tradicional e dos limitados usos), e de ser destinado à preservação para o futuro (Ariño, 2007).

A conservação desse legado se fundou em discursos autorizados (Smith, 2006) que apartaram cultura e natureza ao considerar os usos sociais como degradantes, ao desarticular os aspectos intangíveis dos bens a serem conservados, ao privar pela proteção de criações "civilizatórias" em detrimento das criações anônimas da cultura popular em sua interação com o meio ambiente e ao considerar como atribuição exclusiva de especialistas nomeados pelo poder público, a ordenação do legado cultural e natural. A comprometer ainda mais a dualidade, 
a criação de instituições públicas não dialógicas para os dois tipos patrimoniais: o cultural e o natural.

A institucionalização do patrimônio em si e sua separação em cultural e natural reforçaram os entendimentos da purificação das formas de pensar ser possível gerir a natureza e a cultura.

\section{Do puro ao híbrido}

A construção de "zonas ontológicas distintas" entre o natural e o cultural por meio do exercício de purificação é uma das características mais típicas de nosso tempo, o que, na concepção de Latour (1993), não passa de uma ilusão moderna, uma vez que durante o processo de purificação ocorre exatamente o seu oposto: a constante construção de novos híbridos de natureza e cultura processo denominado por esse autor de translação.

Se recuperarmos as antinomias centrais natureza versus cultura (ou história) e sujeito versus estrutura, conforme sugeridas por Anderson (1984), percebemos que

[...] ambas conotam o mesmo dilema teórico, o de decidir se as relações entre os termos opostos são de continuidade (solução reducionista) ou de descontinuidade (solução autonomista ou emergente). A cultura é um prolongamento da natureza humana, exaustivamente analisável em termos de biologia da espécie, ou ela é uma ordem suprabiológica que ultrapassa dialeticamente seu substrato orgânico? A sociedade é a soma das interações e representações dos indivíduos que a compõem, ou ela é sua condição supraindividual, e como tal um "nível" específico da realidade? (Viveiros de Castro, 2002, p.302)

Como postulou Bruno Latour (2001, p.337), a dicotomia natureza versus cultura é eminentemente arma de "ressentimento e vingança" na imposição de um domínio (natureza) e de uma atividade (ciência) como fundamentos esclarecedores da política, configurando um método de classificação para separar o moderno do tradicional (Latour, 1994, p.70-1), para distinguir o que pertenceria ao passado (crença, ou a confusão entre coisas e homens) do que apontaria para o futuro (conhecimento, ou a capacidade de discriminar objetos e sujeito).

Mas a todo tempo "somos confrontados com evidências crescentes de que nossa tentativa de entender a natureza e a cultura como entidades separadas não se adequa mais ao nosso mundo" (Hinchliffe; Woodward, 2004, p.3), pois esse se conforma de forma híbrida. A hibridização não significa o encontro de duas culturas originais e o consequente nascimento de uma terceira, mas antes o surgimento de um “terceiro espaço" no qual se pode desenvolver novas posições (Bhabha, 1994). Isso é o que se viu em relação ao sentido do patrimônio ao longo do século XX.

\section{O patrimônio como categoria híbrida}

Se em sua formulação inicial o patrimônio instituído foi concebido como materialidade, expressão de uma história, uma identidade e um fazer de poucos, 
proclamados como de uma nação, hoje deparamos com entendimentos ampliados, expressos tangível e intangivelmente, de grupos e em espaços múltiplos, cuja proteção vai além de imobilizar e/ou segregar espaços culturais e naturais.

O discurso autorizado na constituição inicial definiu o patrimônio como objetos materiais, lugares de beleza estética e frágeis, a justificar a necessidade da proteção pública. Esse discurso dispôs que o patrimônio é algo que se "encontra", que seu valor é inato, sua essência é algo que "falará" às gerações presentes e futuras e assegurará sua compreensão e seu "lugar" no mundo (Smith, 2011: $43)$.

A ideia de discurso, para Laurajane Smith, não se refere simplesmente ao uso de palavras ou linguagem, mas a uma prática social na qual significados, formas de conhecimento e experiência, relações de poder e ideologias são incorporados e reproduzidos via linguagem. Isso explica por que o discurso autorizado sobre o patrimônio se tornou altamente ativo na última parte do século XX, "quando aparecem e se definem os conceitos-chave" (Ariño, 2007, p.74), com sentidos expressos em normas e técnicas definidas por legislação e acordos nacionais e internacionais para a gestão do que se convencionou como patrimônio (Smith, 2006).

Uma instituição produto e produtora desse sentido foi a Organização das Nações Unidas para a Educação, a Ciência e a Cultura (Unesco), criada em 1946, a quem coube formular diretrizes, definir critérios e prioridades para a proteção do patrimônio cultural instituído em escala internacional.

Ao longo da segunda metade do século XX e início do XXI, as disposições da Unesco expressaram as mudanças de entendimentos de cultura, arte, história, cidade e natureza, que favoreceram a que os bens considerados patrimônio deixassem de ser referidos como "monumentos" resguardados da ação humana.

A cultura, antes tida como um atributo de eruditos, passou a ser vista como "um sistema de concepções herdadas, expressa em formas simbólicas por meio das quais os homens comunicam, perpetuam e desenvolvem o seu conhecimento e as atitudes perante a vida" (Hunt, 1992, p.97). A arte deixou de ser considerada exclusivamente como a criação da elite, resultante de um aprendizado formal, para ser vista como uma forma de expressão das relações humanas, pois "nada existe realmente a que se pode dar o nome de Arte. Existem somente artistas [...]. Arte, com A maiúscula, não existe" (Gombrich, 1999, p.3). A escrita da História se voltou para os estudos antropológicos e passou a contemplar todos os atores sociais e todos os campos nos quais se expressa a atividade humana, pois "onde o homem passou, onde deixou qualquer marca de sua vida e de sua inteligência, aí está a História" (Le Goff, 2003, p.530). A aceleração da urbanização fez que a cidade histórica deixasse de ser pensada como um museu e passasse a ser compreendida como um tecido vivo, no qual se veem arquiteturas, praças, ruas, formas de sociabilidade; um espaço não homogêneo e articulado, mas um mosaico, muitas vezes sobreposto, que expressa tempos e modos dife- 
renciados de viver (Zanirato; Ribeiro, 2006). A natureza deixou de ser imaginada como mero objeto, fonte de recursos naturais, objetiva e desumanizada para se converter num conjunto de elementos naturais e culturais que propicia o desenvolvimento da vida em todas as suas formas (Lenoble, 2002).

Tais sentidos se fizeram presentes na Convenção da Unesco para a Proteção do Patrimônio Mundial, Cultural e Natural, de 1972, quando as categorias patrimônio cultural, natural e mundial foram tratadas na expectativa de aproximar cultura e natureza como bens cujos sentidos depreendem dos contextos sociais nos quais são gerados. Assim, se consideraram como patrimônio as obras do homem e da natureza e a importância de integrar esse patrimônio à vida coletiva e de associar sua proteção aos programas de planificação geral (Unesco, 1972).

É importante considerar o contexto no qual se insere a Convenção de 1972, uma vez que não é possível dissociá-la de outros movimentos e tendências envolvendo temas culturais como a Mesa de Santiago do Chile, do mesmo ano, na qual o papel dos museus foi colocado em questão e a ideia de um museu integral se conformou como resposta ao distanciamento das instituições museológicas tradicionais frente a realidades sociais diversas. Ao museu integral caberia o papel de conscientizador e transformador social, fundamentando a tese de que os bens culturais possuem significados intrinsecamente associados e traduzidos em diferentes contextos sociais.

Ambas, Mesa de Santiago do Chile e Convenção de 1972, apresentaram questões que se tornaram desafios às sociedades contemporâneas, pressionadas por buscar soluções a problemas sociais de grande amplitude, aos quais se agregavam questões ambientais e cuja perspectiva de futuro estava a exigir novas abordagens para o patrimônio.

Uma contribuição significativa para o alargamento do conceito foi dada em 2003, quando da incorporação das "criações do povo" ao patrimônio cultural e a consideração de que os bens das diversas culturas expressos em saberes e fazeres informam a dimensão imaterial da criação humana. No texto da Convenção da Unesco para a Salvaguarda do Patrimônio Cultural Imaterial (2003) constou a importância da proteção desse tipo patrimonial que compreende:

[...] as práticas, representações, expressões, conhecimentos e técnicas - junto com os instrumentos, objetos, artefatos e lugares culturais que lhes são associados - que as comunidades, os grupos e, em alguns casos, os indivíduos reconhecem como parte integrante de seu patrimônio cultural. (Unesco, 2003)

Em acordo com o documento citado, trata-se de um patrimônio

[...] que se transmite de geração em geração, é constantemente recriado pelas comunidades e grupos em função de seu ambiente, de sua interação com a natureza e de sua história, gerando um sentimento de identidade e continuidade e contribuindo assim para promover o respeito à diversidade cultural e à criatividade humana. (ibidem) 
O texto explicitou a importância da diversidade cultural e afirmou que toda cultura se desenvolve em relação com as características de seu entorno natural, que influencia as formas particulares de vida e gera sentimentos de identidade. A conservação desse patrimônio se faria mediante a participação "mais ampla possível das comunidades, dos grupos e dos indivíduos que criam, mantém e transmitem esse patrimônio" (ibidem).

Nessa Convenção se podem observar mais claramente novos sentidos e usos do patrimônio instituído ao definir que esse se exprime nos conhecimentos e usos relacionados com a natureza e que, para protegê-lo é preciso apoiar seus portadores e o contexto social e cultural nos quais estes se encontram, pois disso depende a transmissão desse saber. Por isso, a proteção deve levar em consideração as dinâmicas da criação, da renovação e da transmissão cultural.

Ainda assim, lembra Smith (2006), trata-se de um discurso autorizado, que tende a privilegiar suposições europeias e geralmente ocidentais e no qual dissonâncias e diferenças são reguladas, arbitradas e gerenciadas. Ao afirmar a "profunda interdependência que existe entre o patrimônio cultural imaterial e o patrimônio cultural e natural", os riscos gerados pela globalização e resultados antagônicos como aproximações culturais e exacerbação de intolerâncias e destruição de referências culturais, a Convenção entranhou-se no caráter híbrido do patrimônio, concebendo-o em sua gênese com a proeminência dos atores sociais diretamente afetados por ele, suas diferentes manifestações e expressões, o que solicita novos e diversos instrumentos legais a compor o léxico patrimonial tal como a ideia de salvaguarda.

O texto da Convenção de 2003 da Unesco em seu artigo 2 definiu salvaguarda como um conjunto de medidas que buscam garantir "a viabilidade do patrimônio cultural imaterial". Essas medidas, que são da ordem da identificação, documentação, pesquisa, promoção, valorização, apresentam como objetivo fundamental atuar na continuidade do bem cultural, em sua reprodutibilidade social através da transmissão. Ainda que a Convenção reconheça procedimentos e quadros normativos nacionais e locais, busca a universalização de princípios metodológicos que se organizam em torno da ideia de diversidade cultural, comunidade de destino e, fundamentalmente, do papel dos atores sociais, detentores do patrimônio.

Em contraste com a concepção do patrimônio edificado, externo aos sujeitos, o patrimônio imaterial se voltava para o reconhecimento desses sujeitos, secretado no interior de uma cadeia de transmissão, formatado na tradição que se reinventa e se traduz na complexa sinergia entre o meio e o tempo.

Assim, foi no patrimônio imaterial que as manifestações culturais, antes invisibilizados pelo patrimônio monumental, adquiriram maior representatividade. Ele possibilitou a primazia do processo de constituição dos objetos culturais frente aos conceitos de autenticidade, antiguidade, raridade. Ele também permitiu compreender que o "patrimônio" não é uma "coisa", não é um "local", 
um edifício ou outro objeto material; como lembra Laurajane Smith (2006), o patrimônio é o que acontece nesses lugares. Embora os lugares sejam importantes, diz essa autora, o uso desses é que os tornou patrimônio, não o mero fato de sua existência. Assim, para ela, todo patrimônio é intangível.

Nessa perspectiva é menos relevante o patrimônio do que seu processo gerador, a patrimonialização, compreendida como "o processo pelo qual um coletivo reconhece o estatuto de patrimônio aos objetos materiais e imateriais de maneira a se perceber como herdeiro dos que os produziram e com a obrigação de preservá-los e transmiti-los" (Davallon, 2014), é um processo que se formaliza por meio de ações que garantem sua viabilidade. O reconhecimento do valor do objeto, a produção de um conhecimento sobre ele, a declaração da condição de patrimônio, a conservação e a extroversão desses objetos culturais constituem-se nos cinco pontos identificados por Davallon como parte dessa operação patrimonial.

E não foram somente as dimensões intangíveis das culturas que foram incorporadas ao processo de patrimonialização. Desde as fases iniciais de aparecimento do patrimônio instituído, o que a literatura filosófica ocidental chamava de "natureza" compunha o rol de bens patrimonializáveis sob o conceito de paisagem.

A Convenção de 1972 explicitou que a paisagem compreendia tanto a criada pela natureza quanto a que expressava a interação dessa com a cultura. Ela podia ser produzida intencionalmente, como os jardins, ou ser "prova manifesta da sua dinâmica natural ao longo do tempo", assim como podia ser uma paisagem associativa, definida pelos significados simbólicos, não imediatamente tangíveis à natureza (Unesco, 1972). O artigo $1^{\circ}$ das Diretrizes para a Aplicação da Convenção do Patrimônio Mundial de 1992 refirmou que a paisagem é "uma obra conjugada do homem e da natureza: pode ser um jardim ou um parque, uma paisagem relíquia ou uma paisagem viva, marcada por sua história, ou uma paisagem que associa o elemento natural a um fato religioso, artístico ou cultural" (Unesco, 1992).

Nova mudança se viu em 2011, na 36 a Sessão de sua Conferência Geral, que incluiu o sentido de "paisagem histórica urbana", algo que expressa a pertinência ao território vivido e sentido e que não se limita aos espaços naturais, pois inclui também o meio urbano. A paisagem, como dispôs o documento, vai além do "centro histórico" e inclui o contexto urbano mais amplo e seu ambiente geográfico (Unesco, 2011).

Enfim, a paisagem passou a ser compreendida como uma realidade dinâmica, resultante de processos ambientais e culturais que sucedem ao longo do tempo no território e fruto de distintos agentes que interveem na construção e uso dos espaços (Zanirato, 2020).

Dentro do campo semântico do patrimônio, que remete mais ou menos de maneira sistemática à noção de monumento pela memória e traços - necessa- 
riamente plurais - do passado, inserem-se os produtos da ação humana em interação com objetos, conhecimentos, representações e seres não-humanos (Bouchenaki, 2003). Assim, os acervos e as listas que a comunidade internacional, as nações e/ou os grupos reconhecem e valorizam como patrimônio se fazem híbridos no que diz respeito às categorias classificatórias as quais os elementos pertencem, enquanto os processos que conduzem ao estatuto de patrimônio apresentam-se relativamente homogêneos e unificados.

Todavia, recorda-se que as categorias em uso nas políticas, nas práticas ou nas ferramentas legislativas de regulamento do patrimônio, são ligadas a entendimentos e sistema conceitual de origem ocidental, com as quais as várias configurações locais lidam e negociam para conseguir entrar no palco do patrimônio mundial ou nacional, e implementar medidas de reconhecimento e de salvaguarda.

Seguindo as orientações do perspectivismo, conceitualizadas no seio da antropologia das ontologias (Viveiro de Castro, 2002; Descola, 2005), é possível perceber que além da hibridez dos elementos tidos como patrimônio, escondem-se outras formas de hibridez nas concepções sobre classificar, gerir, cuidar, conservar, salvaguardar e proteger.

É nessa direção que reportamos uma vez mais a Laurajane Smith (2006) acerca da classificação e gestão do que se concebe como patrimônio instituído, posto que o discurso relativo à conservação apela à participação social, mas mistifica e naturaliza as relações de poder existentes por não considerar que a participação implica em reconhecer outros saberes que não a escolaridade ocidental, expressa nas falas dos especialistas moldados pela formação acadêmica (Waterson; Smith, 2010).

A assunção da condição híbrida implica quebrar também esses pontos, reconhecendo efetivamente a participação dos detentores do patrimônio na gestão, em seu sentido amplo.

Tem-se então que as referências puras que faziam sentido nas concepções iniciais do patrimônio estão a se modificar na experiência vivida e expressam o quadro contemporâneo no qual a proliferação, como aborda Jean-Louis Tornatore, aponta para um movimento cada vez mais expansivo e globalizante e no qual a justificativa do Estado Nação já não se coloca de forma definidora para a ação patrimonial. Múltiplos agentes, sentidos e significados conferem ao termo uma amplitude semântica, operando como categoria de pensamento (Gonçalves, 2009), expressão política da memória (Candau, 2011), modernidade, ruptura e reinvenção do Ocidente (Poulot, 2009), transbordamento e excesso (Jeudy, 2008).

A percepção de patrimônio como um bem com múltiplos sentidos e funcionalidades, um conceito híbrido, alterado gradativamente, tem passado de um campo semântico a outro, do monumental apanágio de elites sociais e econômicas ao vernacular; do cultural e monumental ao natural e imaterial e dos altos lugares da história universal aos espaços definidores de identidades locais. 


\section{Considerações finais}

As formas instituídas do pensamento moderno que separaram cultura e natureza se fizeram presentes nas formulações iniciais do patrimônio formalizado por ação pública. A força desse tipo de pensamento marcou modos de se conceber o patrimônio, ainda que se tenham observadas mudanças ao longo do século XX e início do XXI, com a incorporação de aspectos naturais e intangíveis nessa categoria analítica.

Seguem desafios de transpor asserções ainda vinculadas às concepções da Modernidade, entre elas as relacionadas à gestão desse patrimônio que não só mantém instâncias separadas de conservação de bens culturais e bens naturais, como sustenta a gestão no âmbito dos conhecimentos de especialistas, sem a efetiva inclusão dos detentores do patrimônio no processo de seleção, classificação, difusão e meios de proteção. Finalmente, há que se ter claro que se trata do patrimônio instituído, gerido e controlado por instituições de poder, e diferente do patrimônio sentido, vivido. Sem essa distinção, todo entendimento de mudança permanece confinado à retórica e a um desafio sistêmico real.

\section{Referências}

ANDERSON, P. A crise da crise do marxismo. São Paulo: Brasiliense, 1984.

ARIÑO, A. La invención del patrimonio y la sociedad del riesgo. In: RODRIGUEZ M. A. La sociedad de la cultura. Barcelona: Ariel, 2007. p.71-88.

BHABHA, H. K. The Location of Culture. London, Routledge, 1994.

BECK, U. Risk Society - Towards a New Modernity. London: Sage Publications, 1992.

BECK, U.; GIDDENS, A.; LASH, S. Modernização reflexiva: política, tradição e estética na ordem social moderna. São Paulo: Editora da Unesp, 1997.

BONFIL BATALLA, G. Nuestro patrimonio cultural: un laberinto de significados. In FLORESCANO, E. (Coord.) El patrimonio nacional de México. México: Conaculta, 1997. p.28-56.

BOUCHENAKI, M. The interdependency of the tangible and intangible cultural heritage. In: $14^{\text {th }}$ ICOMOS General Assembly and International Symposium. Victoria Falls, Zimbabwe, 2003, p. 27-31.

CANDAU, J. Memória e Identidade. São Paulo: Contexto, 2011.

CHOAY, F. A alegoria do patrimônio. São Paulo: Estação Liberdade; Ed. Unesp, 2001. COMISSÃO GUlbenKIAN. Para abrir as ciências sociais. São Paulo: Cortez Ed. 1996.

DAVALLON, J. À propos des régimes de patrimonialisation: enjeux et questions. In: Patrimonialização e sustentabilidade do património: reflexão e prospectiva. Lisboa: s. n., 2014.

DESCOLA, P. Par-de là nature et culture. Paris: Gallimard, 2005.

DURKHEIM, E. Da divisão do trabalho social. Lisboa: Presença, 1984. 
FLORIT, L. O lugar da 'natureza' na teoria sociológica contemporânea. In: XXIV ENCONTRO ANUAL DA ANPOCS. Petrópolis, Anpocs, Petrópolis, out. 2000.

FRANKLIN, S.; LURY, C.; STACEY, J. Global Nature, Global Culture. London: Sage Publications Ltd., 2000.

GOMBRICH, E. A História da arte. Rio de Janeiro: LTC, 1999.

GONÇALVES, J. R. S. O patrimônio como categoria de pensamento. In. ABREU, R.; CHAGAS, M. (Org.) Memória e patrimônio: ensaios contemporâneos. 2.ed. Rio de Janeiro: Lamparina, 2009. p.25-33.

HARTOG, F. Régimes d'historicité. Présentisme et expériences du temps. Paris: Seuil. 2003.

HEINICH, N. O Inventário: um patrimônio em vias de desartificação? PROA-Revista de antropologia e arte, n. 5, 2014.

HINCHLIFFE, S.; WOODWARD, K. Introduction. In: HINCHLIFFE, S.; WOODWARD, K. (Ed.) The Natural and the Social: Uncertainty, Risk, Change. London; New York: Routledge, 2004. p.1-6.

HUNT, L. A nova história cultural. São Paulo: Martins Fontes, 1992.

JEUDY, H. P. La machinerie patrimoniale. Paris: Circé, 2008.

JONES, O. Nature-Culture. Ed. R. Kitchin, N. Thrift . International Encyclopedia of Human Geography, Elsevier, v.7, t.1, p.309-323, 2009.

LATOUR, B. We Have Never Been Modern. Cambridge: Harvard University Press, 1993. - Jamais fomos modernos. São Paulo: Ed. 34, 1994.

. When things strike back: a possible contribution of 'science studies' to the social sciences. British Journal of Sociology, v.51, n.1, p.107-23, 2000.

. A esperança de Pandora. São Paulo: Edusc, 2001.

. The Social as Association. In: GANE, N. The Future of Social Theory. London:

Ed. Continuum, 2004.

LE GOFF, J. História e memória. Campinas: Unicamp, 2003.

LEITE, M. Hegemonia e crise na noção de 'Gene' nos 50 anos do DNA. Anais do $49^{\circ}$ Congresso Nacional de Genética. Águas de Lindoia, 2003.

LENOBLE, R. História da ideia de Natureza. Lisboa: Edições 70, 2002.

LOWENTHAL, D. Natural and Cultural Heritage. International Journal of Heritage Studies. v.11, n.1, p.81-92, March 2005.

MCCORMICK, J. Rumo ao paraiso: a história do movimento ambientalista. Rio de Janeiro: Relume Dumará, 1992.

NASH, R. Wilderness and the American Mind. New Haven: Yale University Press, 2014.

PARSONS, T. The Structure of Social Action: a study in social theory with special reference to a group of recent European writers. New York: Free Press of Glencoe, 1961.

POULOT, D. Uma história do patrimônio no Ocidente. São Paulo: Estação Liberdade, 2009. 
POULOT, D. A razão patrimonial na Europa. Revista do Patrimônio Histórico e Artístico Nacional, n.34, 2012.

RAUTENBERG, M. Patrimônio, continuidade ou ruptura no uso e nas representações dos lugares? Jornades Nacionals de Patrimoni Etnològic, Barcelona, 2010.

SHAPIRO, R.; HEINICH, N. Quando há artificação. Sociedade e Estado, v.28, n.1, Jan./Apr. 2013.

SMITH, L. Uses of Heritage. New York: Routledge, 2006.

El “espejo patrimonial” ¿ilusión narcisista o reflexiones múltiples? Antípoda, Rev. Antropol. Arqueol. Bogotá, n.12, p.39-63, Enero-Junio 2011.

STRATHERN, M. Reproducing the future. Essay on anthropology, Kindship and the new reproductive technologies. Nova York: Routledge, 1992.

STROSS, B. The Hybrid Metaphor: From Biology to Culture. The Journal of American Folklore, v.112, n.445, p.254-67, Summer 1999.

UNESCO. Convención para la protección del patrimonio mundial natural y cultural, 1972. Disponível em: <www.unesdoc.unesco/org/>. Acesso em: 14 fev. 2018.

Diretrizes para a Aplicação da Convenção do Patrimônio Mundial, Cultural e Natural, 1992. Disponível em: <http://www.unesco.org/culture/ich/index. php?lg=es\&pg=00026>. Acesso em: 28 fev. 2018.

Convenção para a salvaguarda do patrimônio cultural imaterial, 2003. Dispo-

nível em: <www.unesco.org>. Acesso em: 25 nov. 2016.

Recommandation sur le paysage urbain historique - Projet de texte revise. Paris:

Unesco, 2011. Disponível em: <http://whc.unesco.org/fr/activites/638/>. Acesso em: 14 fev. 2018.

VALDEBENITO, R. M. G. Identidades territoriales y Patrimonio Cultural: la apropiación del patrimonio mundial en los espacios urbanos locales. Revista F@ro, ano 1, n.2, p.32-41, 2005.

VIVEIROS DE CASTRO, E. A inconstância da alma selvagem (e outros ensaios de antropologia). São Paulo: Cosac \& Naify, 2002.

WATERTON, E.; SMITH, L. The recognition and misrecognition of community heritage, International Journal of Heritage Studies, v.16, n.1-2, p.4-15, 2010.

WEBER, M. A “objetividade" do conhecimento nas ciências sociais. In: COHN, G. Max Weber. São Paulo: Ática, 1997.

ZANIRATO, S. H. Paisagem cultural e espírito do lugar como patrimônios. Em busca de um pacto social de ordenamento territorial. Revista CPC, n.29, junho de 2020 (prelo).

ZANIRATO, S. H.; RIBEIRO, W. C. Patrimônio cultural: a percepção da natureza como um bem não renovável. Revista Brasileira de História, v.26, n.51, p.251-62, 2006.

RESUMO - O conceito de patrimônio é uma construção social, definida a partir da percepção do risco de desaparecimento de bens da criação humana e bens da natureza. A institucionalização de práticas patrimoniais em domínios separados cultura e natureza 
expressou o dualismo cartesiano mais amplo, por compreender de modo desarticulado os aspectos tangíveis e intangíveis dos bens a serem conservados e por ter em conta a valoração de criações “civilizatórias” e a menos valia das criações da cultura popular em sua interação com o meio ambiente. No entanto, as práticas conservacionistas desde o final do século XX acabaram por mostrar quão híbrido é o conceito, e que a eficácia da conservação só pode ocorrer a partir da superação da dualidade material/imaterial e da interação de diferentes saberes, tantos os científicos quanto os empíricos.

PALAVRAS-CHAVE: Patrimônio, Híbrido, Práticas conservacionistas, Natureza, Cultura.

ABSTRACT - The concept of heritage is a social construction, defined from the perception that natural and human-created goods run the risk of disappearing. The institutionalization of heritage practices in separate domains of culture and nature expresses the broader Cartesian dualism, disarticulating the tangible and intangible aspects of the items to be preserved, assigning value to "civilizing" creations and diminishing the value of the creations of popular culture in their interaction with the environment. However, conservationist practices since the end of the 20th century have shown how hybrid this concept is, and that conservation can be effective only by overcoming the material/ immaterial duality and through the interaction of different types of knowledge, both scientific and empirical.

KEYWORDS: Heritage, Hybrid, Conservationist practices, Nature, Culture.

Sílvia Helena Zanirato é doutora em História, professora no curso de Gestão Ambiental e nos Programas de Pós-Graduação em Ciência Ambiental e em Mudança Social e Participação Política, Universidade de São Paulo. @ - shzanirato@usp.br / https://orcid.org/0000-0002-9484-5359.

Tatiana Gomes Rotondaro é doutora em Sociologia, professora do Departamento de Economia e do Programa de Pós-Graduação em Ciência Ambiental, Universidade de São Paulo. @ - tatiana.rotondaro@usp.br / https://orcid.org/0000-0002-0208-0732.

Maria Letícia Mazzucchi Ferreira é doutora em História, professora do Departamento de Museologia, Conservação e Restauro, Universidade Federal de Pelotas.

@ - leticiamazzucchi@gmail.com / https://orcid.org/0000-0003-3379-6378.

Cyril Isnarté doutor em Antropologia, pesquisador do Centre National de la Recherche Scientifique, França e do Institut d'Ethnologie Méditerranéenne, Européenne et Comparative, Aix Marseille Université CNRS. @- isnartc@gmail.com /

https://orcid.org/0000-0001-9251-1542.

Recebido em 25.5.2020 e aceito em 18.2.2021.

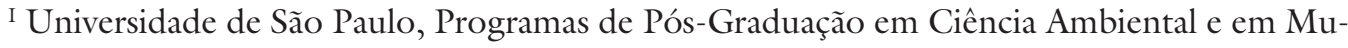
dança Social, São Paulo, São Paulo, Brasil.

II Universidade de São Paulo, Programa de Pós-Graduação em Ciência Ambiental, São Paulo, São Paulo, Brasil.

III Universidade Federal de Pelotas, Departamento de Museologia, Conservação e Restauro, Pelotas, Rio Grande do Sul, Brasil.

IV Université CNRS, Institut d'Ethnologie Méditerranéenne, Européenne et Comparative, Aix Marseille, France. 